\title{
Correction to: SGLT2 inhibitors: a novel choice for the combination therapy in diabetic kidney disease
}

Honghong Zou ${ }^{\dagger}$, Baogin Zhou ${ }^{\dagger}$ and Gaosi Xu*

\section{Correction to: Cardiovasc Diabetol (2017) 16:65} https://doi.org/10.1186/s12933-017-0547-1

Following publication of the original article [1] the authors reported that the first affiliation ("Medical Center of the Graduate School, Nanchang University, China") had been added in error, and that the correct author information is as given in this erratum.

The original article can be found online at https://doi.org/10.1186/ s12933-017-0547-1.

\section{Publisher's Note}

Springer Nature remains neutral with regard to jurisdictional claims in published maps and institutional affiliations.
Received: 19 February 2018 Accepted: 19 February 2018

Published online: 09 March 2018

\section{Reference}

1. Zou H, Zhou B, Gaosi X. SGLT2 inhibitors: a novel choice for the combination therapy in diabetic kidney disease. Cardiovasc Diabetol. 2017;16:65. https://doi.org/10.1186/s12933-017-0547-1.

*Correspondence: gaosixu@163.com

${ }^{+}$Honghong Zou and Baogin Zhou contributed equally to this work

Department of Nephrology, The Second Affiliated Hospital of Nanchang

University, No. 1, Minde Road, Donghu District, Nanchang Zip Code:

330006, People's Republic of China 